smaller, therefore the contradiction with previous results is not resolved by this possibility.

Alternatively, the proxy data used by Cárdenas and Harries might reflect more than just nutrient availability. For example, peaks in continental weathering often coincided with continental collisions and the building of mountain belts (Fig. 1). In addition to increasing nutrient runoff into the ocean, these large tectonic disturbances also increase the number of geographic barriers to the movement of animals. This can occur as a direct result of uplift, or through the transport of sediments into formerly uniform carbonate substrates. Such sediment could act as barriers to carbonate-dependent taxa, driving speciation and origination in spite, rather than because, of higher nutrient levels. This alternative model is consistent with the link between high origination rates and lowered sea level, which also results in the emergence of geographic barriers among marine populations as sills rise and ocean gateways close. A model of tectonic forcing agrees with biological views on speciation, which always require some interruption of gene flow to get started.

Regardless of which environmental factor, or factors, ultimately drove variations in origination, Cárdenas and Harries $^{4}$ convincingly show that abiotic ones were important. We thus have to accept that both biotic and abiotic factors may be relevant on similar timescales, and that models based solely on biotic interactions cannot tell the full story of marine evolution.
Wolfgang Kiessling is at the Museum für Naturkunde, Humboldt University, Invalidenstr. 43, 10115 Berlin, Germany.

e-mail:wolfgang.kiessling@mfn-berlin.de

\section{References}

1. Jablonski, D., Roy, K. \& Valentine, J. W. Science 314, 102-106 (2006).

2. Alroy, J. Proc. Natl Acad. Sci. USA 105, 11536-11542 (2008).

3. Kiessling, W., Simpson, C. \& Foote, M. Science 327, 196-198 (2010)

4. Cárdenas, A. L. \& Harries, P. J. Nature Geosci. 3, 430-434 (2010).

5. Martin, R. E. Palaios 11, 209-219 (1996).

6. Palumbi, S. R. Trends Ecol. Evol. 7, 114-118 (1992).

7. Stanley, S. M. Paleobiology 12, 89-110 (1986).

8. Bambach, R. K., Knoll, A. H. \& Sepkoski, J. J. Proc. Natl Acad. Sci. USA 99, 6854-6859 (2002).

9. Foote, M. Paleobiology 32, 345-366 (2006).

10. Kiessling, W. \& Aberhan, M. Paleobiology 33, 414-434 (2007).

11. Bambach, R. K. Paleobiology 19, 372-397 (1993).

12. Venditti, C., Meade, A. \& Pagel, M. Nature 463, 349-352 (2010).

\section{Published online: 23 May 2010}

\title{
CLIMATE CHANGE IMPACTS
}

\section{Malaria management}

Where malaria is rife, millions of people die of the disease each year, significant parts of the workforce are incapacitated and tourism suffers. The impact of malaria could be exacerbated by climate change, because the Plasmodium parasites that cause the disease thrive in the warmth. Their reproduction rate has been estimated to rise by a factor of up to three by 2050 based on climate projections.

But according to Peter Gething and colleagues (Nature 465, 342-345; 2010), any climate-induced increases in the prevalence of malaria should be easy to overcome with moderate efforts at disease control. The researchers studied global maps of malaria occurrence in about 1900, and the prevalence of the Plasmodium falciparum parasite in 2007 , to see how the burden of malaria has changed. The maps show that the geographical extent of malaria has dropped dramatically during this period, despite undisputed climate warming. The disease covered about $58 \%$ of the Earth's land surface in 1900, but only about 30\% at the start of the twenty-first century. In addition, in three quarters of the locations where malaria was common in 1900 , the number of secondary infections generated from a single infection with the parasite plummeted by more than one order of magnitude between the two surveys. Any expansions of the disease

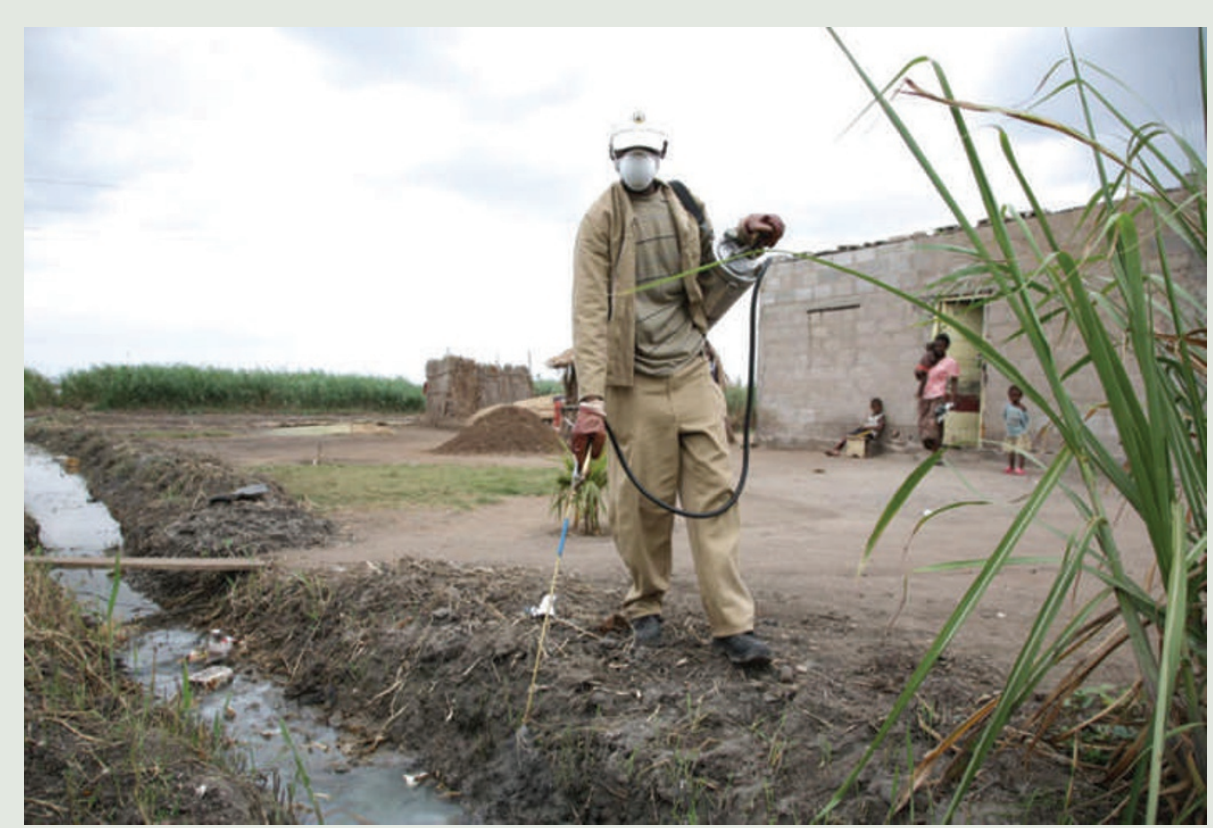

due to twentieth-century temperature rise were thus vastly overcompensated by other factors.

The success in the fight against malaria is likely to be mostly attributable to the sustained implementation of measures to control the disease, as well as to urbanization and economic development. Disease control measures are most effective at the fringes of the regions where malaria prevails - the same locations where climate change is assumed to play the largest role by expanding the current geographical extent of the disease.

In light of the historical evidence, the international community needs to face one important conclusion: if we fail to contain this crippling disease in the course of the next century, we cannot offload the blame on climate change.

HEIKE LANGENBERG 